\title{
Genotype $\times$ Environment Interaction for Milk Production of Daughters of Australian Dairy Sires from Test-Day Records
}

\author{
B. J. Hayes, ${ }^{*, 1}$ M. Carrick, ${ }^{*}$ P. Bowman, ${ }^{*}$ and M. E. Goddard ${ }^{\star} \dagger$ \\ "Victorian Institute of Animal Science, \\ Department of Natural Resources and Environment, \\ Attwood, Victoria, 3049, Australia \\ tInstitute of Land and Food Resources, \\ University of Melbourne, \\ Parkville, Victoria, 3052, Australia
}

\begin{abstract}
In Australia, dairy farming is carried out in environments that vary in many ways, including level of feeding and climate variables such as temperature and humidity. The aim of this study was to assess the magnitude of genotype $\times$ environment interactions $(\mathrm{G} \times \mathrm{E})$ on milk production traits (milk yield, protein yield, and fat yield) for a range of environmental descriptors. The environment on individual test days was described by herd size (HS), average herd protein yield (AHTDP), herd test-day coefficient of variation for protein yield (HTDCV), and temperature humidity index (THI). A sire random regression model was used to model the response of a sire's daughters to variation in the environment and to calculate the genetic correlation between the same traits measured in two widely different environments. Using test-day records, rather than average lactation yields, allowed exploitation of withincow variation as well as between-cow variation at different levels of AHTDP, and led to more accurate estimates of sire breeding values for "response to environment." The greatest $\mathrm{G} \times \mathrm{E}$ observed was due to variation in AHTDP, with a genetic correlation of 0.78 between protein yield when AHTDP $=0.54 \mathrm{~kg}$ and protein yield when AHTDP $=1.1 \mathrm{~kg}$ (the 5th and 95th percentile of the distribution of AHTDP). The $\mathrm{G} \times \mathrm{E}$ was also observed for THI, with a genetic correlation of 0.90 between protein yield at the 5th and 95th percentile of THI. The use of response to environment estimated breeding values to improve the accuracy of international sire evaluations is discussed.
\end{abstract}

(Key words: genotype $\times$ environment interaction, herd test day, random regression)

Received January 30, 2003.

Accepted June 20, 2003.

Corresponding author: B. Hayes; e-mail: ben.hayes@akvaforsk. nlh.no. Current address: AKVAFORSK, Institute for Aquaculture Research, University of Norway, Ås, Norway.
Abbreviation key: ADHIS = Australian Dairy Herd Improvement Scheme, AHTDP = herd average herd protein yield on individual test days, $\mathbf{G} \times \mathbf{E}=$ genotype $\times$ environment interaction, HS $=$ herd size, HTDCV $=$ herd test-day coefficient of variation for protein yield, THI = temperature humidity index.

\section{INTRODUCTION}

The environments in which dairy farming is practiced in Australia vary in many ways, including the level of feeding and climate variables such as temperature and humidity. If a genotype $\times$ environment interaction $(\mathbf{G} \times \mathbf{E})$ exists, the differences between sires in the milk yield of their daughters will vary from one environment to another and may cause reranking of sires between production environments.

Most studies investigating interaction between genotype and feeding level have reported high to very high genetic correlations between feeding level. Cromie et al. (1997) reported correlations across feeding levels of 0.95 for milk yield between two classes of dairy herds in the Irish Republic, with the mean concentrate input either 1583 or $540 \mathrm{~kg} / \mathrm{cow}$. Using herd production level as a surrogate for the level of feeding, Veerkamp and Goddard (1998) reported a genetic correlation of 0.79 between Australian dairy herds with $<20 \mathrm{~kg}$ of milk per day and herd with $>24 \mathrm{~kg}$ of milk per day. Calus et al. (2002) reported similar results for genetic correlations between extreme classes of herd production level in Dutch dairy cattle. The magnitude of $\mathrm{G} \times \mathrm{E}$ can be more substantial than these studies suggest if the performance of different genotypes are compared across more diverse levels of feeding. For example, Kolver et al. (2002) reported significant $\mathrm{G} \times \mathrm{E}$ for milk traits and fertility traits when the performance of imported and New Zealand Holstein Friesian dairy cows were compared on all pasture or TMR diets.

Genotype $\times$ heat stress interaction for milk production has mainly been investigated with genotypes defined at the level of breed in extreme environments. Significant 
$\mathrm{G} \times \mathrm{E}$ has been found under these conditions (Sahota and Gill, 1991). Few studies have investigated genotype $\times$ heat load interactions within the Holstein breed. Ravagnolo and Misztal (2000) concluded there was considerable genetic variation for heat tolerance at high values of a THI. They estimated that the additive genetic variance for loss of production due to heat stress, at $36^{\circ} \mathrm{C}$ and $50 \%$ humidity, would be as high as the general additive genetic variance for milk yield.

Most studies investigate genotype $\times$ environment interaction for milk production by defining milk production in different environments as different traits, and then calculating genetic correlations between these traits (Cromie et al., 1997; Veerkamp and Goddard, 1998). An alternative to partitioning the environments into classes is to consider the environmental descriptor as a continuous variable in a random regression model. Many environmental descriptors are continuous variables, for example herd production level, herd size, and temperature. Fikse et al. (2002), in a study of Australian, US, Canadian, and South African Guernsey herds, used a random regression model to assess the size of $\mathrm{G} \times \mathrm{E}$ effect for a number of different environmental descriptors. The model allowed estimation of the genetic correlation between any points along the environmental trajectory. Fikse et al. (2002) found genetic correlations lower than 0.91 between extreme environments for herd peak milk yield, within herd standard deviation, and annual rainfall.

The aim of this study was to assess the magnitude of $\mathrm{G} \times \mathrm{E}$ effect on milk production (milk yield, protein yield, and fat yield) for a range of environmental descriptors. Environmental descriptors considered were herd size (HS), average herd protein yield on individual test days (AHTDP), herd test-day coefficient of variation for protein yield (HTDCV), and temperature humidity index (THI). Coefficients of variation for herd test-day yields were used rather than standard deviations, as the HTDCV was less correlated with production levels. Temperature humidity index has been shown to be a robust indicator of dairy production losses due to high temperature and humidity in Australia (Mayer et al., 1999) and other countries (Hahn, 1969; Johnson, 1985).

A random regression approach was used to calculate genetic correlations of milk yield, protein yield, and fat yield between extremes of environmental descriptors. The effects of using herd test day information compared to whole lactation data to estimate $\mathrm{G} \times \mathrm{E}$ was investigated.

\section{MATERIALS AND METHODS}

\section{Data}

A total of over 13 million test-day milk yield, protein yield, and fat yield records of Holstein-Friesian cows were extracted from the Australian Dairy Herd Improvement Scheme (ADHIS) database. The data extraction process involved checks for acceptable ranges and conditions according to ADHIS edit procedures for production traits and other variables. Test-day records between January 1, 1998, and December 31, 2001, of cows sired by artificial insemination bulls were considered for this study. Records were edited on the following criteria: tests before $6 \mathrm{~d}$ or after $305 \mathrm{~d}$ were excluded; and cows were included in the analysis only if they had valid first-lactation records and 6 herd test days in the first lactation (we analyzed first-lactation records but used all lactation records to calculate herd production levels).

Additional data edits eliminated sires with fewer than 50 daughters in the edited dataset, sires that had progeny in fewer than three herds, herds that used fewer than three sires. The final dataset included 870,637 records on 110,192 cows in 2008 herds, and 51,159 herd test days.

For each locality defined by an ADHIS record of the postal code of the herd, the centroid latitude and longitude was obtained from Geoscience Australia. Postal codes representing large regional cities or capitals were removed from the study, leaving approximately $400 \mathrm{ru}-$ ral postal codes. The climate data used were taken from the Queensland Department of Natural Resources DataDrill project. The DataDrill records are derived from interpolation of meteorological station data onto a $5-\times$ 5 -km grid across Australia (Jeffrey et al., 2001). Their method used daily measured data from over 4620 locations during the period 1957 to the present. These data are interpolated onto a two-dimensional spline providing the "best estimate" of daily weather variables on a $5-\times 5-\mathrm{km}$ grid. Most dairy farms in the study were located near a number of meteorological stations recording daily weather measurements. Thus for each test day, and up to $30 \mathrm{~d}$ prior to the test day, weather conditions recorded included maximum and minimum temperatures, rainfall, pan evaporation, radiation, and vapor pressure. Relative humidity at maximum and minimum temperatures, dew-point temperature, and various temperature-humidity-radiation indices were derived from them. Dew point temperature, a function of vapor pressure (vp), is the temperature below which dew forms and is a measure of absolute humidity: Dew point temperature:

$$
T_{d p}=(237.7 \times \ln (v p / 6.1078)) /(17.269-\ln (v p / 6.1078)),
$$

where $\mathrm{T}_{\mathrm{dp}}$ is in degrees Celsius and vp is in hectopascals. From this, THI was derived from dry-bulb temperature $\left(\mathrm{T}_{\mathrm{db}}\right)$, following Mayer et al. (1999) as: 


$$
T H I=T_{d b}+0.36 \times T_{d p}+41.2
$$

\section{Environmental Descriptors}

Herd test-day production averages were calculated by correcting test-day records of protein yield for age and stage of lactation using ADHIS multiplicative correction factors, summing corrected records over all cows recorded on that test day (not just first-parity cows) and dividing by the number of cow-tests on that day. Coefficients of variation (HTDCV) were calculated by dividing the standard deviations of corrected protein yields within a herd test day by AHTDP and multiplying by 100 . Only herd test days with more than 20 cows recorded were included in the analysis.

Herd size was the total number of cows milking for a herd in that year season (before data edits were applied). Only herds with HS greater than 50 were included in the analysis.

In preliminary investigations of our data, THI on the test day and 1, 2, 3, and $4 \mathrm{~d}$ previously had significant effects on herd test-day yields. The THI for $0,1,2,3$, and $4 \mathrm{~d}$ prior to test day were averaged to obtain the values corresponding to each herd test day, and this value, which hereafter is designated as THI, was used as an environmental descriptor. The effect of increasing THI on AHTDP was investigated by fitting a cubic spline, according to the approach of Verbyla et al. (1999).

\section{Statistical Analysis}

All data analyses were performed by residual maximum likelihood using the ASREML software (Gilmour et al., 1999).

Transformation for heterogeneous variance. For analysis of AHTDP, we applied a power transformation (Box-Cox) to milk production data with the aim of accounting for heterogeneity of variance with changing production level. The Box-Cox transformation was

$$
y_{i}^{\lambda}=\left\{\begin{array}{l}
\frac{y_{i}^{\lambda}-1}{\lambda} \cdot \text { when } \cdot \lambda \neq 0 \\
\log \left(y_{i}\right) \cdot \text { when } \cdot \lambda=0
\end{array}\right.
$$

The value of $\lambda$ was calculated as $1-\beta$, where $\beta$ is the linear coefficient of regression of $\ln \left(\sigma_{\overline{H Y S}}\right)$ on AHTDP. The value of $\beta$ was 1.2. Therefore, a log transformation of the trait was used when AHTDP was the environmental descriptor. Investigation showed transformation was unnecessary for other environmental descriptors.

Random regression analysis. For $H S$, the model used to analyze the data was

$$
\begin{aligned}
y_{i j k l}=\mu+H T D_{i} & +Y S_{j}+\sum_{n=1}^{3} A_{n} \mathbf{x}_{n}+\sum_{n=1}^{8} \mathbf{D}_{n} \mathbf{Z}_{n}+P_{l} \\
& +\sum_{m=0}^{1} S_{k n} W_{n}+e_{i j k l},
\end{aligned}
$$

where $y_{i j k l}$ is yield of milk, protein or fat from the $i$ th herd test day, $j$ th year season of calving, $k$ th sire and $l$ th cow in her first lactation, $\mu$ is the overall mean, $H T D_{i}$ is the effect of the $i$ th herd test day; $Y S_{j}$ is the effect of the $j$ th year season of calving, $x_{n}$ is the nth-order orthogonal polynomial corresponding to age on day of test, $A_{n}$ is a fixed regression coefficient of milk, protein or fat yield on age at test, $Z_{n}$ is the nth-order polynomial corresponding to DIM at test, $D_{n}$ is a fixed regression coefficient of milk, protein or fat yield on DIM, $P_{l}$ is the effect of the $l$ th cow, $S_{k n}$ is a random regression coefficient on the environmental descriptor for the $k$ th sire, $W_{n}$ is the nth-order polynomial corresponding to HS, and $e_{i j k l}$ is the vector of residual effects.

For AHTDP, HTDCV, and THI, the model used to analyze the data was

$$
\begin{aligned}
y_{i j k l}=\mu+H T D_{i}+ & Y S_{j}+\sum_{n=1}^{3} A_{n} \mathbf{x}_{n}+\sum_{n=1}^{8} \mathbf{D}_{n} \mathbf{Z}_{n}+\sum_{m=0}^{1} P_{\ln } W_{n} \\
& +\sum_{m=0}^{1} S_{k n} W_{n}+e_{i j k l}
\end{aligned}
$$

where variables are as defined above, and $P_{l n}$ is a random regression coefficient on the environmental descriptor for the $l$ th cow.

Initial investigations showed heat stress only affected milk production above 60 THI (see results). When THI was the environmental descriptor, all values of THI below 60 were given the value of 60 .

The following (co) variance structure was assumed for both models:

$$
\operatorname{Var}\left[\begin{array}{c}
\mathbf{S} \\
\mathbf{P} \\
\mathbf{E}
\end{array}\right]=\left[\begin{array}{ccc}
\mathbf{G} \otimes \mathbf{A} & \mathbf{0} & \mathbf{0} \\
\mathbf{0} & \mathbf{P} \otimes \mathbf{I} & \mathbf{0} \\
\mathbf{0} & \mathbf{0} & \mathbf{I e}
\end{array}\right],
$$

where $\mathbf{G}=$ sire genetic variance-covariance matrix among random regression coefficients (and traits in the MT model), $\mathbf{A}=$ additive numerator relationship matrix between the sires, the sires and dams of the sires, and known pedigree of these animals as far back as the year 1950 (6170 sires total). Both the sire of a sire and dam of a sire were included. The matrix $\mathbf{P}$ was the cow variancecovariance matrix among random regression coefficients (single value for HS), and e was the single error and $\mathbf{I}$ represents an identity matrix with ones on the diagonal. 
It is possible that there may be some confounding between stage of lactation and sensitivity to AHTDP, especially in seasonally milked herds, where cows with the same AHTDP also have similar DIM. To test for confounding between stage of lactation and sensitivity to AHTDP (e.g., a sire's sensitivity to stage of lactation (persistency) may be confused with sensitivity to AHTDP $(\mathrm{G} \times \mathrm{E})$ in our test-day model), two steps were taken. The correlation between DIM and AHTDP was calculated. In addition, a model with random regression parameters for both DIM and AHTDP was fitted. The model fitted was

$$
\begin{gathered}
y_{i j k l}=\mu+H T D_{i}+Y S_{j}+\sum_{n=1}^{3} A_{n} \mathbf{x}_{n}+\sum_{n=1}^{8} \mathbf{D}_{n} \mathbf{Z}_{n}+\sum_{m=0}^{1} P_{\ln } W_{n} \\
+\sum_{m=0}^{1} S_{k n} W_{n}+\sum_{m=0}^{2} R_{\ln } \mathrm{V}_{n}+\sum_{m=0}^{2} T_{k n} V_{n} e_{i j k l},
\end{gathered}
$$

where parameters are defined above, and additionally $R_{l n}$ is a random regression coefficient on DIM for the $l$ th cow, $T_{k n}$ is a random regression coefficient on DIM for the $k$ th sire, $V_{n}$ is the nth-order polynomial corresponding to DIM, and $e_{i j k l}$ is the vector of residual effects. Confounding between stage of lactation and sensitivity to environment would result in reduced $\mathrm{G} \times \mathrm{E}$ with this model, compared with the previous model.

The random regression model allows one to calcuate the genetic correlation between yield measured at any two levels of the environment variable. Generally, the more different the values of the two environment variables, the lower the genetic correlation.

\section{Assessment of Additional G×E Information from Within-Cow Variation}

The random regression model for AHTDP (and HTDCV and THI) uses two sources of variation to estimate "response to environment" EBV (linear component of the random regression) for each sire. These are: 1) Between-cow variation. Using a single record per cow, one can regress the yield of a sire's daughters against the mean yield of the herd. A steeper slope for a sire indicates greater sensitivity of his daughters to variation in the environment as measured by herd average yield. 2) Within-cow variation. For each individual cow with multiple test-day records, a within-cow regression of test yield on herd mean test-day yield can be calculated. A cow with a steep slope is highly sensitive to the environment, as indicated by the herd average yield on a test day. This slope can be treated as a new trait and the breeding value of her sire for the trait estimated. We wished to determine the contribution of each source of variation to the response to environment EBV estimated from the random regression model for AHTDP described above (linear solution for each sire).

To determine the contribution of between-cow variation, a random regression model was fitted to single testday lactation records. Lactations were considered to be comprised of 10 intervals (TD1 to TD10), the first from six to 30 DIM, and subsequent intervals were of $30-d$ intervals each, except the 10th, which had 35 (270 to 305 DIM). The intervals were analyzed separately. For each cow, a single test day record within the interval was extracted. The environmental indicator was AHTDP. The model used to analyze each TD was

$$
\begin{aligned}
y_{i j k l}=\mu+H T D_{i}+Y S_{j}+ & \sum_{n=1}^{3} A_{n} \mathbf{x}_{n}+\sum_{n=1}^{8} \mathbf{D}_{n} \mathbf{Z}_{n}+\sum_{m=0}^{1} S_{k n} W_{n} \\
& +e_{i j k l},
\end{aligned}
$$

where variables are defined as above. The first-order random regression sire slopes $\left(\mathrm{S}_{\mathrm{k} 1}\right)$, were allocated to the vectors SLOPETD $_{1}$ to SLOPETD ${ }_{10}$ for the 10 testday intervals.

To determine the contribution of the second source of variation an additional analysis was conducted in two steps. In the first step, transformed (natural log) protein yield records were analyzed with a random regression model, with AHTDP as the environmental indicator,

$$
\begin{gathered}
y_{i j l}=\mu+H T D_{i}+Y S_{j}+\sum_{n=1}^{3} A_{n} \mathbf{x}_{n}+\sum_{n=1}^{8} \mathbf{D}_{n} \mathbf{Z}_{n} \\
+\sum_{m=1}^{1} P_{\ln } W_{n}+e_{i j l},
\end{gathered}
$$

where variables are defined above. Subsequently, cow solutions for mean protein yield $\left(P_{l 0}\right)$ and the slope for protein yield $\left(P_{l 1}\right)$ were reanalyzed using a multiple-trait sire model. The model used to analyze the cow mean and slope solutions was

$$
y_{t i j k}=\mu_{t}+H_{i}+Y S_{j}+S_{t k}+e_{t i j k}
$$

where $y_{t i j k}$ is the tijkth observation, $\mu_{t}$ is the mean of the $t$ th trait (either cow mean, $\mathrm{t}=0$, or cow slope solution, $\mathrm{t}=1), H_{i}$ is the $i$ th herd, $Y S_{j}$ is defined above, $S_{t k}$ are the sire solutions for sire $k$ and trait $t$, and $e_{t i j k}$ is the vector of residual effects. The $S_{1 k}$ solutions became elements of a vector called SLOPECOW.

To determine the relative contribution of the two sources of information, the following regression equations were fitted: 


$$
\begin{gathered}
\text { SLOPEFULL }=\mu+\sum_{i=1}^{n=10} \beta_{i} \text { SLOPETD }_{i} \\
\text { SLOPEFULL }=\mu+\sum_{i=1}^{n=10} \beta_{i} \text { SLOPETD }_{i} \\
+\beta_{\text {SLOPECOWSLOPECOW },}
\end{gathered}
$$

where $S L O P E F U L L$ is a vector of the first-order sire random regression terms from the full model, $\mu$ is an overall mean, and $\beta_{i}$ and $\beta_{\text {SLOPECOW }}$ are regression coefficients.

For clarity of results, each slope was made independent of the corresponding intercept, by subtracting the product of the genetic regression of the slope on mean and mean for the slope for each sire. The accuracy of prediction of each equation was calculated. The correlation between the linear sire solutions from each analysis was also determined.

\section{RESULTS}

\section{Test for Confounding Between Sire $\times$ Stage of Lactation and Sire $\times$ AHTDP Interaction Effects}

There is known to be genetic variation in the slope of the lactation curve (van der Werf et al., 1998) and hence sire $\times$ DIM interaction. This interaction was not fitted in most of our analyses. This could cause bias in estimation of other interactions such as sire $\times$ AHTDP if DIM and AHTDP were highly correlated. This correlation was only -0.06 . Additionally, when a random regression on DIM was included in the model, the variance of the linear term of the random regression on AHTDP was not reduced, and the genetic correlation between protein yield at the 5th and 95th percentile for AHTDP was the same with and without a random regression term for DIM.

\section{Effect of THI on AHTDP}

The THI had little effect on AHTDP until THI exceeded 60 units, after which there was an approximately linear decline in AHTDP as THI increased, Figure 1 . The value of THI of 60 units corresponds roughly to the upper limit of the thermo-neutral range of lactating cattle (Hahn, 1969).

\section{Correlations Among Environmental Descriptors}

Correlation between environmental descriptors were generally low, Table 1 . As expected, increasing THI was associated with decreased AHTDP.

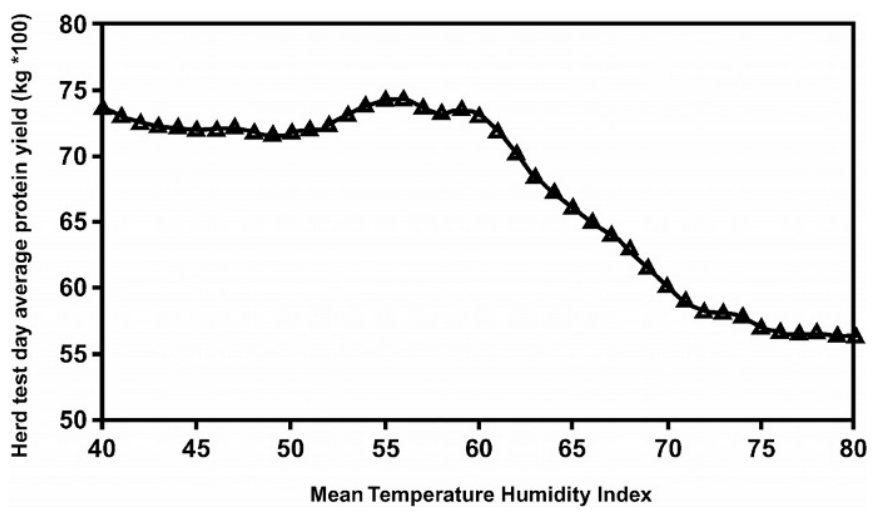

Figure 1. Effect of temperature humidity index (THI) on herd test day average (AHTDP $\times 100$ ). The graph was derived by fitting a cubic spline to THI (following Verbyla et al., 1999).

\section{Change in Heritability over Environment Trajectories and Genetic Correlations Between Extremes of Environmental Descriptors}

Linear regression terms were significant for all environmental descriptors $(P<0.05)$ (results not shown). That is, there is significant variation between sires in sensitivity to these environmental descriptors.

Although the random regression approach allowed us to calculate the heritability at all points along the trajectory of each environmental indicator, for clarity of results we have reported the heritability of each trait only when the environmental variable is at the 5 th percentile of the distribution when the environmental variable is at the 95th percentile of its distribution. The heritability of all traits increased with AHTDP, decreased with larger HTDCV and increasing THI, and did not change with increasing herd size (Table 2).

We have reported the genetic correlation between yield when the environmental variable is at the 5th percentile of the distribution when the environmental variable is at the 95 th percentile of its distribution. The lowest genetic correlation between the 5th and 95th percentile was 0.70 for fat yield with the AHTDP environmental descriptor. Correlations for other environmental descriptors were 0.90 or above, and as high as

Table 1. Correlations among environmental descriptors. ${ }^{1}$

\begin{tabular}{lcccr}
\hline & HS & AHTDP & HTDCV & THI \\
\hline HS & 1.00 & & & \\
AHTDP & 0.11 & 1.00 & & \\
HTDCV & 0.18 & -0.05 & 1.00 & \\
THI & -0.05 & -0.16 & -0.17 & 1.00 \\
\hline
\end{tabular}

${ }^{1} \mathrm{HS}=$ herd size, AHTDP $=$ herd average herd protein yield on individual test days, HTDCV = herd test-day coefficient of variation for protein yield, THI = temperature humidity index. 
Table 2. Heritabilities at 5th and 95th percentiles, and genetic correlation between 5 th and 95th percentiles for environment descriptors.

\begin{tabular}{|c|c|c|c|c|c|c|c|c|c|c|c|}
\hline & \multicolumn{4}{|c|}{ 5th Percentile } & \multicolumn{4}{|c|}{ 95th Percentile } & \multirow{2}{*}{\multicolumn{3}{|c|}{$\begin{array}{c}\text { Genetic correlation } \\
\text { between } 5 \text { th and } 95 \text { th } \\
\text { percentiles }\end{array}$}} \\
\hline & \multirow[b]{2}{*}{ Value } & \multicolumn{3}{|c|}{$\mathrm{h}^{2}$} & \multirow[b]{2}{*}{ Value } & \multicolumn{3}{|c|}{$\mathrm{h}^{2}$} & & & \\
\hline & & Milk & Protein & Fat & & Milk & Protein & Fat & Milk & Protein & Fat \\
\hline HS & 90 & 0.27 & 0.21 & 0.19 & 536 & 0.25 & 0.20 & 0.16 & 0.94 & 0.95 & 0.96 \\
\hline AHTDP & $0.54 \mathrm{~kg}$ & 0.24 & 0.17 & 0.17 & $1.10 \mathrm{~kg}$ & 0.32 & 0.24 & 0.23 & 0.83 & 0.78 & 0.70 \\
\hline HTDCV & $12.3 \%$ & 0.27 & 0.19 & 0.19 & $23.6 \%$ & 0.22 & 0.18 & 0.16 & 0.96 & 0.97 & 0.92 \\
\hline THI & 60.0 & 0.26 & 0.21 & 0.19 & 78.4 & 0.24 & 0.19 & 0.16 & 0.94 & 0.92 & 0.90 \\
\hline
\end{tabular}

0.97 for $H T D C V$. Genetic correlations were generally smaller for fat and protein yields than for milk yields, indicating greater $\mathrm{G} \times \mathrm{E}$ for these traits.

\section{Assessment of Additional G×E Information from Within-Cow Variation}

As described above, sire solutions for the slope of the regression of milk yield on AHTDP were calculated separately for the 10 test-day intervals $\left(S L O P E T D_{1}\right.$ to $S L O P E T D_{10}$ ), for all the test days combined in the full model (SLOPEFULL) and from the slope estimated within individual cows (SLOPECOW). The correlations among these 12 sire solutions are given in Table 3. These are correlations between sire solutions, and so one does not expect them to be 1.0 even if the equivalent genetic correlation is 1.0. The correlations between $S L O P E C O W$ and each of the SLOPETD $i$ are positive. Since the $S L O P E T D_{i}$ are based on between-cow variation, and the SLOPECOW are based on within-cow variation, this is evidence that the effects being detected are real and not an artifact of the complex analysis. Moreover, they show that sensitivity to AHTDP is, to some extent at least, the same trait measured withinor between-cows. This means that both sources of infor- mation can be used to estimate the sensitivity to AHTDP of sires. This is shown by the multiple regression of SLOPEFULL on SLOPECOW and the 10 SLO$P E T D_{i}$. The effect of including SLOPECOW to predict $S L O P E F U L L$ was significant $(P<0.001)$. The accuracy of predicting SLOPEFULL was increased from 0.63, when only the $10 S L O P E T D_{i}$ were included, to 0.82 , when SLOPECOW was included. The accuracy was less than 1, even with individual test-day slopes and $S L O$ $P E C O W$ in the prediction equation, perhaps partly because in the full model some cows had more than 10 test days, while in the individual components model cows were restricted to a maximum of 10 test days.

The correlation of slopes across test days was greatest for test days close to each other in time and was reduced as the length of time between the tests increased, Table 3. SLOPECOW and SLOPEFULL were highly correlated with each other.

\section{DISCUSSION}

We found significant $\mathrm{G} \times \mathrm{E}$ for AHTDP and THI for all traits. The $\mathrm{G} \times \mathrm{E}$ for HTDCV or HS was very small. We chose to analyze HTDCV rather than the standard deviation of herd test-day production, as the standard

Table 3. Correlation of sire slope solutions for protein yield response to AHTDP, for individual test days (TD1 to TD10), sire solutions for individual cow response to changing test day (COW), and the full random regression model (FULL).

\begin{tabular}{|c|c|c|c|c|c|c|c|c|c|c|c|c|}
\hline & TD1 & TD2 & TD3 & TD4 & TD5 & TD6 & TD7 & TD8 & TD9 & TD10 & COW & FULL \\
\hline TD1 & 1 & & & & & & & & & & & \\
\hline TD2 & 0.55 & 1 & & & & & & & & & & \\
\hline TD3 & 0.36 & 0.44 & 1 & & & & & & & & & \\
\hline TD4 & 0.35 & 0.48 & 0.48 & 1 & & & & & & & & \\
\hline TD5 & 0.23 & 0.36 & 0.51 & 0.6 & 1 & & & & & & & \\
\hline TD6 & 0.24 & 0.54 & 0.33 & 0.62 & 0.62 & 1 & & & & & & \\
\hline TD7 & 0.16 & 0.29 & 0.23 & 0.49 & 0.52 & 0.68 & 1 & & & & & \\
\hline TD8 & 0.13 & 0.1 & -0.05 & 0.32 & 0.29 & 0.48 & 0.59 & 1 & & & & \\
\hline TD9 & 0.35 & 0.26 & 0.41 & 0.28 & 0.41 & 0.24 & 0.21 & 0.35 & 1 & & & \\
\hline TD10 & 0.07 & 0.1 & 0.35 & 0.37 & 0.34 & 0.28 & 0.13 & -0.13 & 0.26 & 1 & & \\
\hline COW & 0.19 & 0.31 & 0.28 & 0.53 & 0.39 & 0.49 & 0.5 & 0.29 & 0.32 & 0.32 & 1 & \\
\hline FULL & 0.17 & 0.34 & 0.16 & 0.49 & 0.38 & 0.59 & 0.45 & 0.37 & 0.19 & 0.23 & 0.76 & 1 \\
\hline
\end{tabular}


deviation of herd test-day production is highly correlated with AHTDP and would therefore detect highly correlated $\mathrm{G} \times \mathrm{E}$ effects.

We have assumed that indicators such as AHTDP can be used to define the environment in which a sire's daughters are milked. More specifically, AHTDP was used as a proxy for the level of feeding. Differences in AHTDP could reflect factors other than the level of feeding, such as the average genetic level of the herd. If information on the actual level of feeding were available, this information would allow the milking environment to be defined more accurately, and the estimate of $\mathrm{G} \times \mathrm{E}$ would also be more accurate. However, the actual level of feeding is unavailable for the vast majority of Australian herds, while AHTDP information can readily be derived from milk recording data. Additionally, while differences in AHTDP could reflect factors other than the level of feeding, such as the average genetic level of the herd, the extent of genetic connection between low AHTDP and high AHTDP was sufficiently large that this factor at least should be accounted for in the analysis. For example, the extent of genetic connection between 5th and 95th percentile for AHTDP can be assessed as the proportion of sires with daughter records at or below the 5 th percentile and at or above the $95 \mathrm{th}$ percentile $(0.54 \mathrm{~kg}$ of protein per cow per herd test day and $1.1 \mathrm{~kg}$ of protein per cow per test day, respectively). Sixty-nine percent of sires had both a daughter (or daughters) with a record on a herd test day where AHTDP was at or below the 5th percentile and a daughter (or daughters) with a record on a herd test day where AHTDP was at or above the 95th percentile of AHTDP.

Previous studies using random regression to investigate $\mathrm{G} \times \mathrm{E}$ have used whole lactation records (Fikse et al., 2001; Zwald et al., 2001). In this study, we used herd test-day information to assess $\mathrm{G} \times \mathrm{E}$. When whole lactation records are used, only between-cow variation in performance can be used to estimate $\mathrm{G} \times \mathrm{E}$. If herd test-day records are used, both between-cow and within-cow variation in performance at different levels of environmental descriptors can be used to estimate $\mathrm{G} \times \mathrm{E}$. Investigation showed the response of individual cows to AHTDP within a lactation added considerable information for the estimation of $\mathrm{G} \times \mathrm{E}$. Use of herd testday information also has the advantage that there are more observations per sire, and potentially these observations will be across a wider range of production levels than when whole lactation records are used. Hence, using test-day information allows more accurate prediction of $\mathrm{G} \times \mathrm{E}$.

While there appear to be differences among dairy breeds in the way in which heat stress affects milk production, (Muller and Botha, 1993), our results sug- gest within the Holstein breed there is little variation among sire's daughters for the effect of heat stress on milk production between the 5th and 95th percentile for THI in our data set (genetic correlation of 0.9). Possibly this was because the 95 percentile $(78.4 \mathrm{U})$ does not represent an extreme heat stress. For example, Ravagnolo and Misztal (2000) found the genetic correlation of milk production among moderate and extreme values of THI did not fall below 0.9 until THI exceeded $81 \mathrm{U}$.

The extent of reranking of dairy sires within Australia that we found for the various environmental descriptors can be compared to the extent of reranking between countries. A number of studies have calculated genetic correlations for milk production between dairying countries (Weigel et al., 2001). These studies suggest a genetic correlation for milk production of between 0.79 and 0.96 between Australia and other dairying countries ( 0.79 for Hungary and 0.96 for New Zealand). This and other similar studies use whole lactation records to calculate correlations between countries, rather than test-day records, and so are not directly comparable to our study. Nevertheless, the lowest value for correlation between Australia and another dairying country ( 0.79 with Hungary), is similar to the value of 0.78 we calculated between protein yield at the 5th and 95th percentile for AHTDP. This would appear to suggest production environments within Australia are as diverse as production environments between Australia and other countries. This is possible, given the wide range of climatic, feeding, and management environments that exist in the Australian dairy industry (Veerkamp and Goddard 1998; Mayer et al., 1999).

Studies attempting to determine the cause of reranking of dairy sires between countries implicate similar environmental descriptors to those we found in our within-country study as having the largest $\mathrm{G} \times \mathrm{E}$ component. In the study of Zwald et al. (2001), HolsteinFriesian herds across a number of countries (including Australia) were grouped (clustered) according to their similarity for a range of environmental descriptors. Each cluster was then treated as an environment, and genetic correlations between milk yield in different environments were estimated. The genetic correlations between clusters were less than one in a number of cases, indicating the presence of a $\mathrm{G} \times \mathrm{E}$ interaction. Zwald et al. (2001) concluded that the most important environmental descriptors were herd production level (peak milk yield), herd size, temperature, and standard deviation of milk yield. Fikse et al. (2002), in a study of Australian, US, Canadian, and South African Guernsey herds, used a random regression model to assess the size of $\mathrm{G} \times \mathrm{E}$ effect for a number of different environmental descriptors. They found genetic correlations lower than 0.91 between extreme environments for produc- 
tion level, within-herd standard deviation and annual rainfall.

The small magnitude of $\mathrm{G} \times \mathrm{E}$ for the variables investigated in this study probably does not warrant any change in the national evaluation procedure used by ADHIS. To verify this statement, we investigated the extent reranking of the highest ranked 100 sires (average EBV for protein yield) between the 5th percentile of AHTDP, and 95th percentile of AHTDP for protein yield. An EBV for a sire at a particular level of AHTDP was calculated as his intercept EBV + his slope EBV multiplied by the value of AHTDP. The correlation of rankings of the 100 sires at the 5 th percentile of AHTDP and rankings of the sires' bulls at the 95th percentile of AHTDP was 0.84. This high correlation suggests that a sire's ranking is relatively unaffected by the level of AHTDP at which he is evaluated, within the 5th and 95th percentiles of AHTDP at least.

While our results suggest no change in the national evaluation procedure within Australia is necessary, the "sensitivity to environment" breeding value (sire solutions for the linear component of the random regressions) could be used in other ways to increase the accuracy of sire selection. One possible use of the information, particularly for $\mathrm{G} \times \mathrm{E}$ for AHTDP, would be to improve the accuracy of evaluation of performance of a sire for performance of his daughters in another country with a different average production level. For example, if a US sire performs well in low production herds in the United States, the sire should also perform well in the average herd in Australia. We will test this hypothesis in future work using Australian and US data (US data will be kindly provided by the USDA).

A number of developing countries are currently attempting to increase domestic milk production by importing dairy genetics from developed countries (Vaccaro, 1990). Another potential use of the $\mathrm{G} \times \mathrm{E}$ information for sires is to predict which sires from developed countries will perform well in developing countries with harsh production environments. For example, if a sire's daughters perform well in Australian herds with low levels of production under conditions of high heat stress, that sire's daughters could also perform well in a tropical developing country. Other environmental descriptors characterizing the production environments in developing countries, such as parasite loads, may also need to be considered to evaluate potential export sires.

\section{CONCLUSIONS}

The greatest $\mathrm{G} \times \mathrm{E}$ was observed for AHTDP, with a genetic correlation for protein yield of 0.70 for fat yield between the 5th and 95th percentile of AHTDP (0.54 and $1.10 \mathrm{~kg}$ respectively). The $\mathrm{G} \times \mathrm{E}$ was also observed for THI, with a genetic correlation of 0.90 between the 5th and 95th percentile of THI. The $\mathrm{G} \times \mathrm{E}$ for $H S$ and $H T D C V$ were very small. $\mathrm{G} \times \mathrm{E}$ effect was generally greater for fat yield and protein yield than for milk yield for any given environmental descriptor. The high correlation of sire solutions for response to environment using only between-cow or only within-cow indicates that the $\mathrm{G} \times \mathrm{E}$ effects being detected are real and not an artifact of the complex analysis we used. The withincow information contributed significantly to the accuracy of $\mathrm{G} \times \mathrm{E}$ effects estimated with the full test day model. Individual sire response to environment information could be used to increase the accuracy of predicting the performance of a sire's daughters in another country with a different average production environment.

\section{ACKNOWLEDGMENTS}

The Australian Dairy Research and Development Corporation (Melbourne) funded this project and ADHIS provided the data. We thank Arthur Gilmore for providing the ASREML program. Drs. Kevin Beard and Les Jones are thanked for useful comments and advice.

\section{REFERENCES}

Calus, M. P., A. F. Groen, and G. de Jong. 2002. Genotype × environment interaction for protein yield in dutch dairy cattle as quantified by different models. J. Dairy Sci. 85:3115-3123.

Cromie, A. R., D. L. Kelleher, F. J. Gordon, and M. Rath. 1997. Genotype by environment interaction for milk yield in dairy cattle. Irish Grassl. Animal Prod. Assoc. J. 31:29-35.

Fikse, W. F., R. Rekaya, and K. A. Weigel. 2002. Genotype by environment interaction for milk production in Guernsey cattle. J. Dairy Sci. 86:1821-1827.

Gilmore, A. R., B. R. Cullis, S. J. Welham, and R. Thompson. 1999. ASREML reference manual. NSW Agriculture Biometric Bulletin No. 3. Orange Agricultural Institute. Orange, NSW, Australia.

Hahn, L. 1969. Predicted versus measured production differences using summer air conditioning for lactating dairy cows. J. Dairy Sci. 52:800-801.

Jeffrey, S. J., J. O. Carter, K. B. Moodie, and A. R. Beswick. 2001. Using spatial interpolation to construct a comprehensive archive of Australian climate data. Environ. Model. Software 16:309-330.

Johnson, H. D. 1985. Physiological responses and productivity of cattle. Pages 4-19 in Stress physiology in livestock. Vol 2. Ungulates. M. K. Yousef, ed. CRC Press, Boca Raton, FL.

Kadzere, C. T., M. R. Murphy, N. Silanikove, and E. Maltz. 2002. Heat stress in lactating dairy cows: A review. Livest. Prod. Sci. 77:59-91.

Kolver, E. S., J. R. Roche, M. J. De Veth, L. Thorne, and A. R. Napper. 2002. Total mixed rations versus pasture diets: Evidence for a genotype by diet interaction in dairy cow performance. Proc. N.Z. Soc. Anim. Prod. 62:246-251.

Mayer, D. G., T. M. Davison, M. R. McGowan, B. A. Young, A. L. Matchoss, A. B. Hall, P. J. Goodwin, N. N. Jonsson, and J. B. Gaughan. 1999. Extent and economic effect of heat loads on dairy cattle production in Australia. Aust. Vet. J. 77:804-808. 
Muller, C. J. C., and J. A. Botha. 1993. Effect of summer climatic conditions on different heat tolerance indicators in primiparous Friesian and Jersey cows. S. Afr. J. Anim. Sci. 23:98-103.

Ravagnolo, O., and I. Misztal. 2000. Genetic component of heat stress in dairy cattle, parameter estimation. J. Dairy Sci. 83:2126-2130.

Sahota, R. S., and G. S. Gill. 1991. Genotype × environment interaction for some traits of economic importance of dairy cattle. J. Res. Punjab Agric. Univ. 28:3395-3400.

Vaccaro, L. P. de. 1990. Survival of European Dairy Breeds and Their Crosses with Zebus in the Tropics. Anim. Breed. Abstr. 58:475-494

van der Werf, J. H. J., M. E. Goddard, and K. Meyer. 1998. The use of covariance functions and random regressions for genetic evaluation of milk production based on test day records. J. Dairy Sci. 81:3300-3308.
Veerkamp, R. F., and M. E. Goddard. 1998. Covariance functions across herd production levels for test day records on milk, fat and protein yields. J. Dairy Sci. 81:1690-1701.

Verbyla, A. P., B. R. Cullis, M. G. Kenward, and S. J. Welham. 1999. The analysis of designed experiments and longitudinal data using smoothing splines. Journal of the Royal Statistical Society, Series C 48:269-311.

Weigel, K. A., N. R. Zwald, and R. Rekaya. 2001. International dairy sire evaluation based on a multiple trait BLUP analysis of daughter performance records. Proc. 52nd Annu. Mtg. EAAP.

Zwald, N. R., R. Rekaya, and K. A. Weigal. 2001. Identification of factors that cause genotype by environment interaction in countries that participate in the International Bull Evaluation service. Proc. 52nd Annu. Mtg. EAAP, Budapest, Hungary. 